\title{
Changes in Gastric Function and Healing of Chronic Gastric Ulcers in Aged Rats
}

\author{
Yasuhiro Tsukimi and Susumu Okabe \\ Department of Applied Pharmacology, Kyoto Pharmaceutical University, Yamashina, Kyoto 607, Japan \\ Received December 26, 1994 Accepted February 17, 1995
}

\begin{abstract}
The present study was designed to determine the relationship between changes in gastric function caused by aging and the healing of gastric ulcers. Male Fischer-344 rats (young, 2 months; aged, 24-26 months) were used. Gastric ulcers were induced by luminal application of an acetic acid solution $(60 \%, 0.2$ $\mathrm{ml}, 45 \mathrm{sec}$ ). The basal and histamine-stimulated gastric acid secretions in aged animals were significantly lower than those in young animals. However, the serum gastrin levels were almost the same in the two groups. Gastric mucosal blood flow and mucosal cell proliferation were also decreased in aged animals. Gastric contractile activity induced by electrical vagal stimulation was almost the same in the two groups, while the gastric relaxative response was significantly reduced in aged animals. The development and healing rate of gastric ulcers in aged animals were almost the same as those in young animals. Histologically, regeneration of the ulcerated mucosa was significantly reduced and tissue contraction occurred in aged animals, as compared to in young animals. We concluded that aging had little or no influence on the development and healing rate of gastric ulcers in rats, but the quality of ulcer healing was quite different between young and aged animals, probably resulting from various gastric dysfunctions related to ulcer healing.
\end{abstract}

Keywords: Aging, Acetic acid ulcer, Gastric function, Ulcer healing, Acid secretion

It is well-known that aging causes many functional changes in the body. Several investigators have already reported changes in functions such as gastric secretion $(1,2)$ and the serum gastrin level $(3-6)$, gastric mucosal blood flow (7), bicarbonate secretion (8), and mucosal cell proliferation (4) in the stomach of aged animals. O'Brien et al. (9) reported that aging had no influence on the spontaneous healing of acetic acid ulcers in 2- and 12-monthold rats. In general, gastric acid secretion, gastric mucosal blood flow and mucosal cell proliferation are considered to be profoundly involved in ulcer healing (10). Recently, we reported the importance of tissue contraction in the healing of gastric ulcers in rats $(11,12)$. The aim of this study was to compare the functional changes in the stomachs of young (2-month-old) and aged (24- to 26month-old) rats and to compare the development and healing of chronic gastric ulcers in the two groups.

\section{MATERIALS AND METHODS}

\section{Animals}

Young (2-month-old, 180-200 g) and aged (24- to 26month-old, $420-450 \mathrm{~g}$ ) male Fischer-344 rats (Charles
River, Kanagawa) were used. The animals had free access to laboratory rat chow (CE-2; Nihon Clea, Osaka) and tap water. The animals were deprived of food for $24 \mathrm{hr}$ before the experiments unless stated otherwise. Drinking water was freely available to the animals up to $2 \mathrm{hr}$ before the experiments. During fasting, all animals were kept in mesh-bottom cages to prevent coprophagy. All experiments were performed with paired young and aged animals, and 4 to 10 animals were used for each group.

\section{Induction of acetic acid-induced gastric ulcers}

Acetic acid-induced gastric ulcers were induced by luminal application of an acetic acid solution according to the previously described method (13). Briefly, the abdomen of an animal that had been fasted for $24 \mathrm{hr}$ before the operation was incised and the stomach exposed. Then the anterior and posterior walls of the gastric fundus were clamped together with forceps with a round ring (ID, 9 $\mathrm{mm})$. A $60 \%$ acetic acid solution $(0.2 \mathrm{ml})$ was injected into the clamped lumen with a needle (gauge 21) through the forestomach. Forty-five seconds later, the acid was removed and the abdomen closed. The animal was fed normally thereafter. To determine the sizes of ulcers, animals 
were killed with an overdose of ether at 1,10 and 20 days after acetic acid application, and their stomachs were removed. The stomachs were opened along the greater curvature and rinsed with cold saline. Then the stomachs were pinned to a cork board and then inflated, and the areas $\left(\mathrm{mm}^{2}\right)$ of the ulcers were determined under a dissecting microscope $(\times 10$; Olympus, Tokyo $)$ with a square grid. After determination of the ulcer area, the stomachs were fixed with $10 \%$ formalin for $24 \mathrm{hr}$ for a histological study. With this intraluminal application method, two ulcers developed, one each on the anterior and posterior walls of the stomach. The reason we selected this ulcer model was to avoid any adhesion of the ulcer base to the surrounding organs, which invariably occurs in the case of conventional acetic acid ulcers. In addition, we had already confirmed that these ulcers heal with time in a similar manner and respond equally to antisecretory agents (13). The areas of ulcers on the two walls were summed in the present study.

\section{Histological study}

A histological study was performed according to the method previously described by Ogihara and Okabe (11). At autopsy, small pieces of tissue were embedded in paraffin and sectioned at $4 \mu \mathrm{m}$. Hematoxylin-eosin staining was performed. The lengths of the ruptured muscularis mucosa and regenerative mucosa at the ulcer edges were measured under a light microscope as parameters of tissue contraction and regeneration of the ulcerated mucosa, respectively.

\section{Gastric secretion}

Basal and histamine-stimulated gastric acid secretion were determined by means of pylorus ligation in normal animals. In the case of basal secretion, the pylorus was ligated under ether anesthesia through a short midline incision. The animals were killed $4 \mathrm{hr}$ later, and the gastric contents were collected and analyzed for volume, acidity and pepsin output. The acidity was determined by automatic titration of the contents against $0.1 \mathrm{M} \mathrm{NaOH}$ to pH 7.0 (Comtite 5; Hiranuma, Tokyo). Total acid output (volume $\times$ acidity) was expressed as $\mu \mathrm{Eq} / \mathrm{hr}$. Pepsin activity was determined according to the method of Anson (14). Pepsin output was expressed as mg pepsin/hr. For stimulated secretion, histamine $2 \mathrm{HCl}$ (Nacalai, Kyoto) was injected s.c. at the dose of $20 \mathrm{mg} / \mathrm{kg}$ immediately and $2 \mathrm{hr}$ after ligation.

\section{Serum gastrin level and antral gastrin content}

In a separate study, normally fed animals were anesthetized with ether. Blood was collected from the aorta desendens, and the stomach was immediately removed. The blood was left for $1 \mathrm{hr}$ at room temperature and then cen- trifuged to obtain serum. The antrum was dissected and weighed. Each sample was homogenized in $5 \mathrm{ml}$ of distilled water, and then boiled in a water bath for $20 \mathrm{~min}$. The samples were centrifuged at $3,000 \mathrm{rpm}$ for $20 \mathrm{~min}$, and the supernatant fractions were stored at $-20^{\circ} \mathrm{C}$ before determination of the gastrin concentration. Gastrin was determined by means of a radioimmunoassay (Sanyo-Kasei, Tokyo) and expressed in equivalents of the standard, synthetic human gastrin I ( $\mathrm{pg} / \mathrm{ml}, \mathrm{ng} /$ mucosa).

\section{Cell proliferative activity}

The cell proliferative activity of the fundic mucosa in normal animals was determined by measuring the incorporation of ${ }^{3} \mathrm{H}$-thymidine into DNA under non-fasted conditions according to the previously described method (15). Briefly, the stomach of a normal animal was removed and the fundic mucosa was scraped off with a glass slide. The mucosa was incubated for $30 \mathrm{~min}$ at $37^{\circ} \mathrm{C}$ in medium 199 (Wako Chemicals, Osaka) containing $2 \mu \mathrm{Ci} / \mathrm{ml}^{3} \mathrm{H}$-thymidine (specific activity, $10 \mathrm{Ci} / \mathrm{mmol}$; American Radiolabeled Chemicals, Inc., St. Louis, MO, USA). The reaction was stopped with perchloric acid, followed by hydrolysis with $0.3 \mathrm{~N} \mathrm{KOH}$ to remove RNA. DNA was hydrolyzed with $10 \%$ perchloric acid at $70^{\circ} \mathrm{C}$ for $20 \mathrm{~min}$ and then centrifuged to remove denatured protein. The incorporation of ${ }^{3} \mathrm{H}$-thymidine into DNA was determined by counting $1.0 \mathrm{ml}$ of DNA-containing supernatant in a scintillation counting system. Using calf thymus DNA as a standard, the DNA content of the sample was determined by the procedure of Burton (16), as modified by Giles and Mayers (17). DNA synthesis was expressed as disintegration per minute per microgram of DNA.

\section{Gastric mucosal blood flow}

Gastric mucosal blood flow was measured in rats with 5-day-old ulcers by Laser Doppler flowmetry (model ALF-2100; Advance, Tokyo) under anesthetized conditions induced with urethane $(1.25 \mathrm{~g} / \mathrm{kg}$, i.p.). The abdomen was incised, and the stomach was exposed and mounted on a Lucite chamber, as described by Takeuchi et al. (18). The laser probe was then placed on the ulcer margin or intact mucosa, and the mucosal blood flow was monitored. The data were expressed as percent changes from the value for intact mucosa.

\section{Gastric motility}

Gastric motility was measured with a balloon according to the method of Takeuchi et al. (19). The balloon and support catheter were inserted into the stomach through a small incision in the forestomach. The catheter was connected to a pressure-transducer and a polygraph device (6M-72, San-Ei, Tokyo), and gastric motility was measured continuously as intraluminal pressure. The basal in- 
tragastric pressure was set at $10 \mathrm{cmH}_{2} \mathrm{O}$. Gastric contraction or relaxation was induced by electrical vagal stimulation (20). The left cervical vagus was exposed and cut proximally. Nerve stimulation was carried out, at $0.2 \mathrm{~mA}$ with a square pulse duration of $2 \mathrm{msec}$ and a frequency of $5 \mathrm{~Hz}$, for $5 \mathrm{~min}$ through a bipolar platinum electrode placed distal to the cut in the vagus nerve (SEN-3201; Nihon Kohden, Tokyo). In the case of measurement of gastric relaxation, pretreatment with atropine $(1 \mathrm{mg} / \mathrm{kg}$, s.c.) and phentolamine $(2 \mathrm{mg} / \mathrm{kg}$, s.c.) was performed $30 \mathrm{~min}$ before vagal stimulation. The data obtained were expressed as percent changes from the basal value.

\section{Statistical analyses}

Data are presented as the means \pm S.E.M. for $4-10$ animals. Statistical analyses were performed with the paired Student's $t$-test, values of $\mathrm{P}<0.05$ being regarded as significant.

\section{RESULTS}

\section{Animals}

The mean body and stomach weights of aged animals were markedly higher than those of young animals (Table 1). However, the consumption of food and water by aged animals were almost the same as those by young animals.

\section{Ulcer healing}

When acetic acid was applied to the gastric lumen, kissing gastric ulcers developed on both the anterior and posterior wall, with a $100 \%$ incidence in young and aged animals. The ulcerated areas in young and aged animals at 1 day after acid application were $110.7 \pm 6.4 \mathrm{~mm}^{2}$ and $107.8 \pm 11.5 \mathrm{~mm}^{2}$, respectively (Fig. 1). These ulcers healed with time in a similar manner. The areas of ulceration on the 10th day were $27.3 \pm 1.4 \mathrm{~mm}^{2}$ in young and $29.0 \pm 1.8 \mathrm{~mm}^{2}$ in aged animals. On the 20th day, the ulcer sizes in both groups had decreased further; however, the ulcers of aged animals were small but significantly

Table 1. Various parameters in young and aged Fischer-344 rats

\begin{tabular}{lcccc}
\hline & $\mathrm{n}$ & Young & $\mathrm{n}$ & Aged \\
\hline Age (months) & 8 & 2 & 8 & $24-26$ \\
Body weight $(\mathrm{g})$ & 8 & $193.1 \pm 7.1$ & 8 & $447.5 \pm 16.1^{*}$ \\
Stomach weight $(\mathrm{g})$ & 8 & $0.91 \pm 0.02$ & 8 & $1.62 \pm 0.06^{*}$ \\
Food consumption (g/rat/day) & 8 & $16.9 \pm 0.4$ & 8 & $17.2 \pm 0.3$ \\
Water consumption (ml/rat/day) & 8 & $20.6 \pm 0.5$ & 8 & $21.0 \pm 0.7$ \\
\hline
\end{tabular}

Data are means \pm S.E.M. *: Significantly different from young animals, at $\mathrm{P}<0.05$.

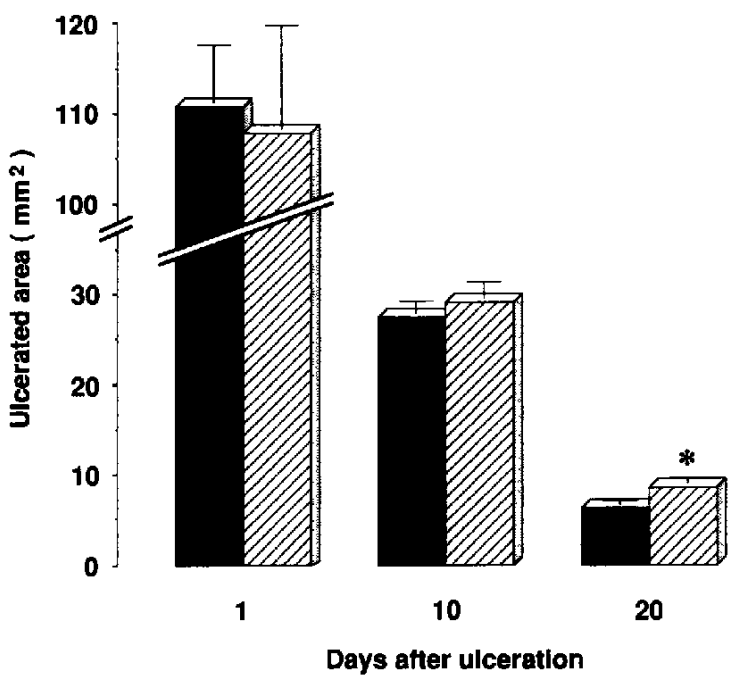

Fig. 1. Effect of aging on development and healing of kissing gastric ulcers. Data are means \pm 1 S.E.M. for 10 animals ( $\square$ : young, W: aged). *: Significantly different from young animals, at $\mathbf{P}<0.05$.

larger than those of young animals. The areas of ulcers in young and aged animals on the 20th day were $6.3 \pm 0.3$ $\mathrm{mm}^{2}$ and $8.6 \pm 0.5 \mathrm{~mm}^{2}$, respectively. There was a significant difference between the two groups.

Histologically, the length of the regenerated mucosa was determined at 10 and 20 days in young animals, the values being $0.21 \pm 0.05 \mathrm{~mm}$ and $1.23 \pm 0.10 \mathrm{~mm}$, respectively (Fig. 2). In aged animals, it was significantly less than that in young animals, the values being $0.00 \mathrm{~mm}$ at the 10th day and $0.81 \pm 0.08 \mathrm{~mm}$ at the 20 th day. The length of the ruptured muscularis mucosa of aged animals was also less than that of young animals, the values being $4.04 \pm 0.13 \mathrm{~mm}$ at the 10 th day (vs $4.50 \pm 0.32 \mathrm{~mm}$ in young animals) and $3.68 \pm 0.14 \mathrm{~mm}$ at the 20 th day (vs $4.10 \pm 0.15 \mathrm{~mm}$ ).

\section{Gastric secretion}

Basal gastric acid secretion (volume and acid output) in young animals was $4.0 \pm 0.3 \mathrm{ml} / \mathrm{rat}$ and $101.3 \pm 8.8$ $\mu \mathrm{Eq} / \mathrm{hr}$, respectively (Fig. 3). Aging caused a significant reduction of basal gastric acid secretion, the values being $1.5 \pm 0.2 \mathrm{ml} / \mathrm{rat}$ and $16.4 \pm 3.9 \mu \mathrm{Eq} / \mathrm{hr}$, respectively. Pepsin output was also decreased in aged animals, the value being $1.4 \pm 0.2 \mathrm{mg}$ pepsin $/ 4 \mathrm{hr}$ vs $3.9 \pm 0.3 \mathrm{mg}$ pepsin $/ 4$ $\mathrm{hr}$ in the young group.

When histamine was administered twice during pylorus ligation, gastric acid secretion in young animals significantly increased. The volume and acid output were $6.7 \pm 0.3 \mathrm{ml} / \mathrm{rat}$ and $222.1 \pm 13.4 \mu \mathrm{Eq} / \mathrm{hr}$, respectively. Again, stimulated gastric acid secretion in aged animals caused by histamine was lower than that in young animals. The values were $3.5 \pm 0.5 \mathrm{ml} / \mathrm{rat}$ and $84.7 \pm 15.5$ 


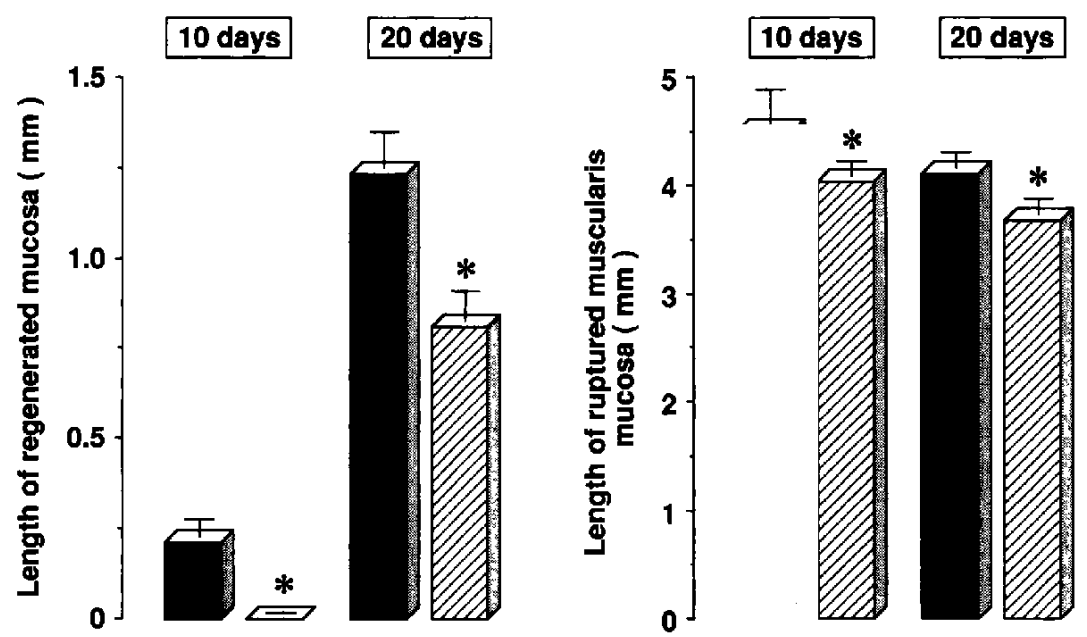

Fig. 2. Effects of aging on the lengths of regenerated mucosa and ruptured muscularis mucosa in animals with ulcers. Data are means \pm 1 S.E.M. for 10 animals ( $\mathbf{Q}$ : young, aged). *: Significantly different from young animals, at $\mathbf{P}<0.05$.

$\mu \mathrm{Eq} / \mathrm{hr}$. The pepsin output in aged animals was also lower than that in young animals.

\section{Gastric mucosal blood flow}

In young animals, the gastric mucosal blood flow at the ulcer edge was markedly increased as compared to that in the intact mucosa, the increase being $149.5 \pm 14.9 \%$ (Fig. 4). The gastric mucosal blood flow at the ulcer edge in aged animals was also increased, the increase, however, was significantly lower than that in young animals, it being $117.1 \pm 6.1 \%$.
Serum and antral gastrin levels and mucosal proliferative activity

The serum gastrin level under non-fasted conditions was not affected by aging, the values being $339.3 \pm 38.2$ $\mathrm{pg} / \mathrm{ml}$ in the young and $294.9 \pm 33.3 \mathrm{pg} / \mathrm{ml}$ in the aged group (Fig. 5). However, the antral gastrin concentration in aged animals was significantly lower than that in young animals, the value being $10.3 \pm 0.5 \mathrm{ng} / \mathrm{mg}$ tissue (vs $25.3 \pm 2.8 \mathrm{ng} / \mathrm{mg}$ tissue in young animals). Furthermore, the mucosal DNA synthetic activity in aged animals was significantly lower than that in young animals, the value being $408.2 \pm 39.3 \mathrm{dpm} / \mu \mathrm{g}$ DNA (vs $830.3 \pm 82.5 \mathrm{dpm} / \mu \mathrm{g}$ DNA in young animals).

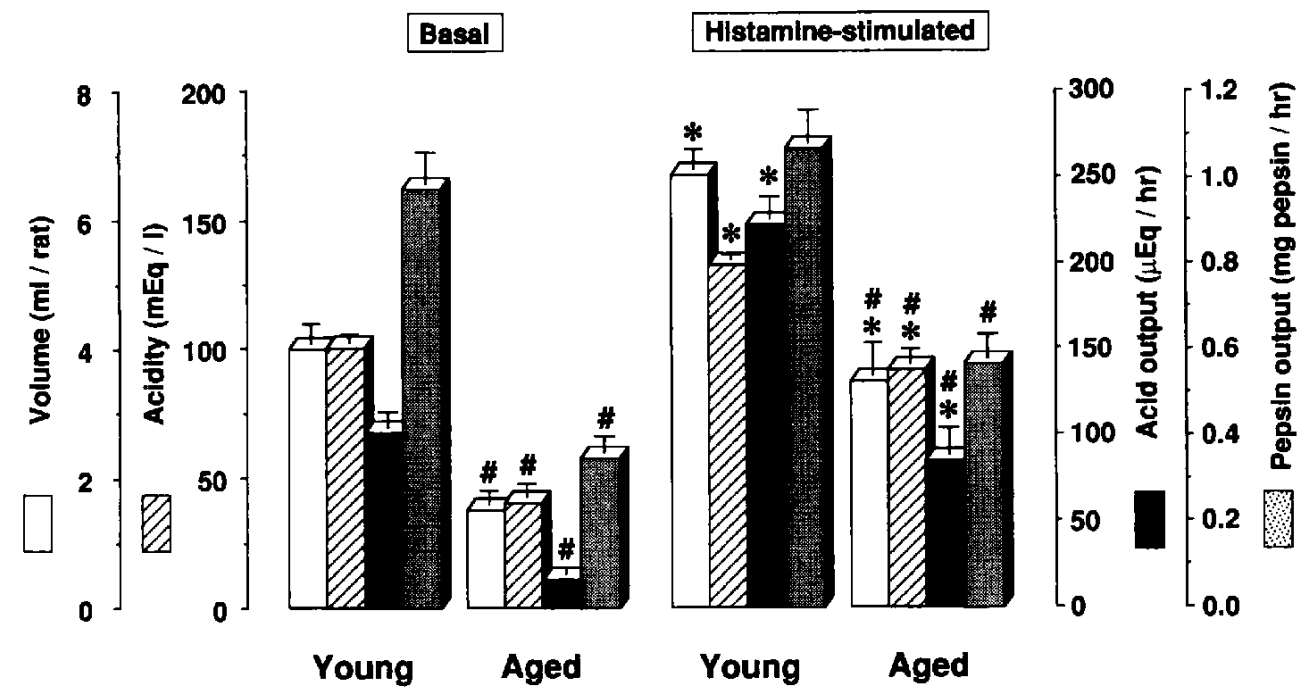

Fig. 3. Effects of aging on basal and histamine-stimulated gastric acid and pepsin secretion. Data are means \pm 1 S.E.M. for 8 animals. ${ }^{*}$ and ": Significantly different from corresponding basal value and young animals, respectively, at $\mathrm{P}<0.05$. 

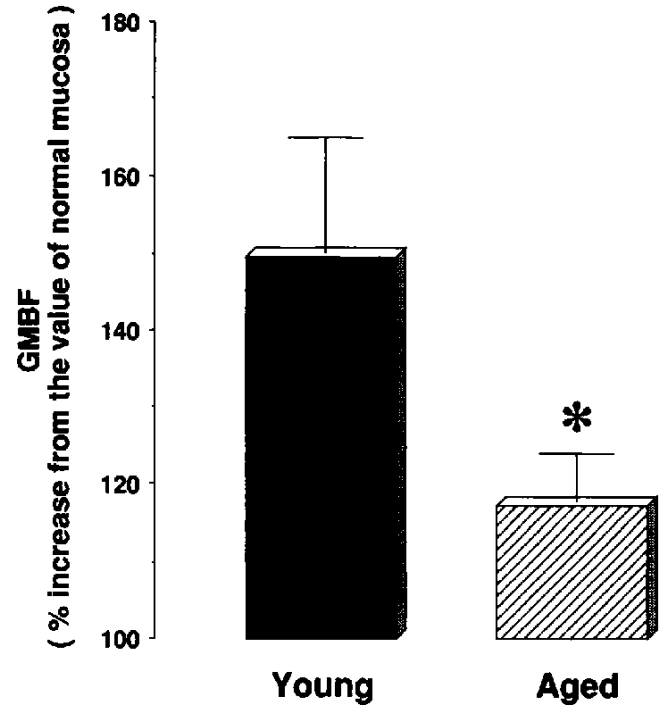

Fig. 4. Effect of aging on gastric mucosal blood flow. Data are means \pm 1 S.E.M. for 5 animals. *: Significantly different from young animals, at $\mathrm{P}<0.05$.

\section{Gastric motility}

The intragastric pressure in young and aged animals increased significantly by 3 -fold when the vagus nerve was stimulated electrically (Fig. 6). There was no significant difference between the two groups. Under the condition of atropine or phentolamine administration, electrical vagal stimulation caused a marked decrease in intragastric pressure by $40 \%$ in young animals. However, the reduction in intragastric pressure was significantly inhibited in aged animals, the reduction being only about $10 \%$.

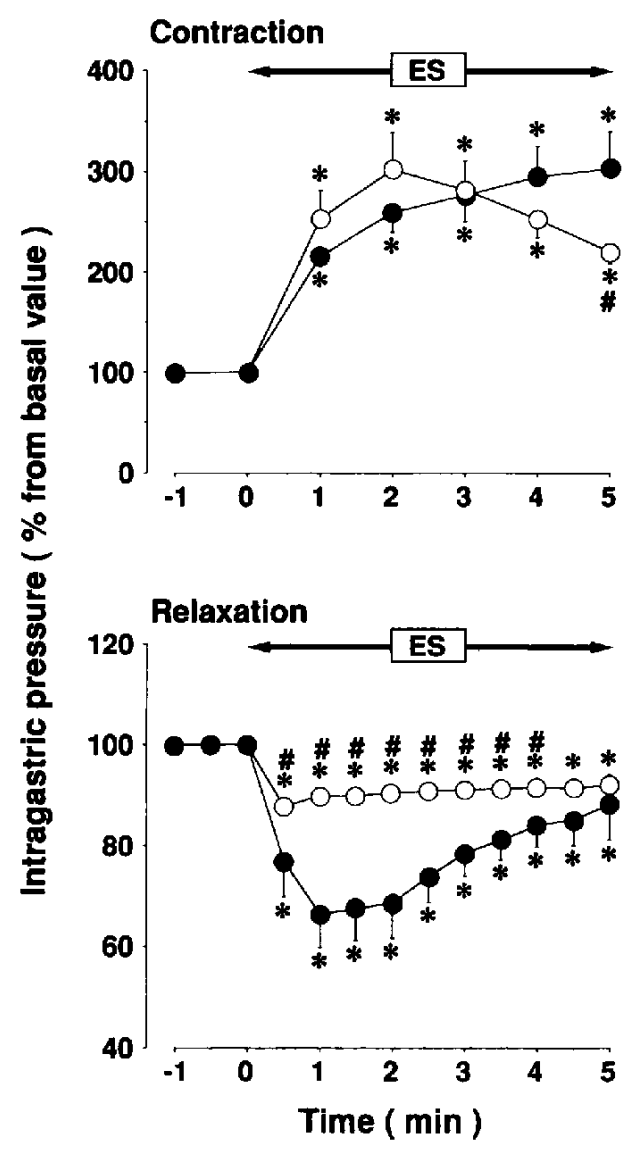

Fig. 6. Effects of aging on contraction and relaxation of the gastric wall induced by electrical vagal stimulation. Data are means \pm 1 S.E.M. for 4 animals (O: young, $O$ : aged). ${ }^{*}$ and ${ }^{*}$ : Significantly different from the basal value and young animals, respectively, at $\mathrm{P}<0.05$.

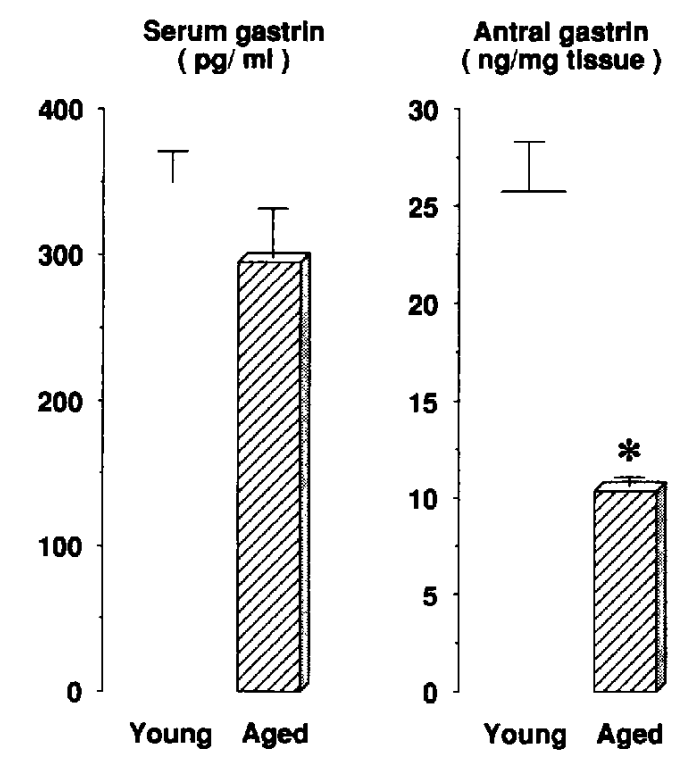
Incorporation of ${ }^{3} \mathrm{H}$-thymidlne

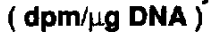

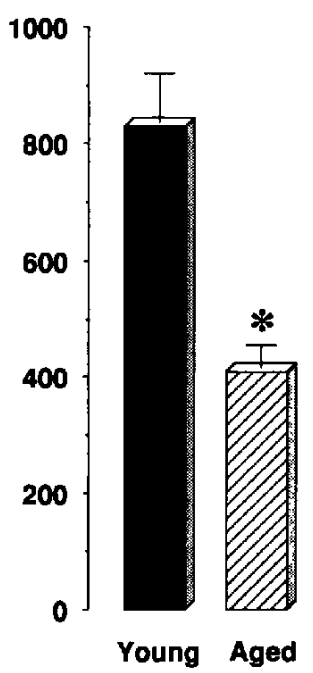

Fig. 5. Effect of aging on serum gastrin level, antral gastrin concentrations and proliferative activity of the gastric mucosa. Data are means \pm 1 S.E.M. for 8 animals. *: Significantly different from young animals, at $P<0.05$. 


\section{DISCUSSION}

In the present study, we used the kissing gastric ulcer model that we recently established (13). Since kissing gastric ulcers do not adhere to the surrounding organs, they are useful for investigating the mechanism of gastric ulcer healing. We confirmed in Fischer-344 rats that the process of gastric ulcer healing could be divided into two phases (the early phase has a fast healing rate and the late phase has a slow healing rate). A histological study showed that regeneration of the ulcerated mucosa was mainly observed in the late phase of the ulcer healing process. This was consistent with our previous report (12). Although aging had no effect on ulcer development and little effect on ulcer healing rate, regeneration of the ulcerated mucosa was decreased and tissue contraction was increased in aged animals, as compared to those in young animals. These results suggest that the quality of ulcer healing differs between young and aged animals. Therefore, we compared gastric functions related to ulcer healing in young and aged animals.

Gastric acid is a negative component for ulcer healing. In fact, repeated administration of histamine was reported to delay ulcer healing (21), and acid inhibitory agents accelerate ulcer healing $(22,23)$. In agreement with the results of others $(1,2)$, we found that the basal and histamine-stimulated gastric acid secretions in aged animals were significantly lower than those in young animals. We found that gastric acid secretion in aged animals was significantly increased as compared to the basal value when histamine was administered. Since $20 \mathrm{mg} / \mathrm{kg}$ of histamine causes a maximal increase of gastric acid secretion in rats $(24,25)$, it is suggested that the number of parietal cells might be decreased in aged animals, rather than that there is a reduction in the response of parietal cells to secretagogues.

Since an increase in or maintenance of the gastric mucosal blood flow at the ulcer margin is generally believed to play an important role in ulcer healing $(26,27)$, it is considered to be a positive component in ulcer healing. In the present study, we confirmed that gastric mucosal blood flow at the ulcer margin was increased as compared to that in the intact mucosa in young and aged animals. Hirose et al. (26) reported that increased gastric mucosal blood flow at the ulcer margin was decreased by indomethacin treatment. Brzozowski et al. (27) reported that nitric oxide (NO) synthase inhibitors decreased the gastric mucosal blood flow at the ulcer margin. From these reports, it is suggested that prostaglandins and NO are involved in the increase or maintenance of gastric mucosal blood flow at the ulcer margin. In aged animals, the increase in blood flow at the ulcer margin was significantly inhibited, probably due to decreases in the prostaglandin content and NO- synthetic system in the gastric mucosa. In fact, the gastric mucosal prostaglandin content and NO-synthetic system in aged animals were reported to be lower than those in young animals $(28-30)$.

In general, serum gastrin is known to increase under conditions of high intragastric $\mathrm{pH}$ (31). However, we found that the serum gastrin level did not increase in aged animals in spite of reduced gastric acid secretion, as compared with that in young animals. Khalil et al. (1) reported that the antral gastrin concentration in aged animals was lower than that in young animals. The decreased antral gastrin concentration may explain why the serum gastrin level did not increase in aged animals. Several investigators suggested that mucosal cell proliferation is one of the crucial factors in the healing of gastric and duodenal ulcers $(32,33)$. In a study involving the incorporation of ${ }^{3} \mathrm{H}$-thymidine into DNA, we found that the gastric mucosal proliferative activity in aged animals was significantly lower than that in young animals. In fact, the histological study showed that regeneration of the ulcerated mucosa was significantly less in aged animals, as compared to that in young animals. That the serum gastrin levels were almost the same in young and aged animals suggests that the response of gastric mucosal cells to gastrin decreased with aging or aging influenced other growth factors. Several investigators reported that the serum gastrin level in aged animals was significantly lower than that in young animals $(3-6)$. The reason for the difference in the results between these groups and ours appears to be the different experimental conditions. They determined serum gastrin levels under fasted or postprandial conditions, while we determined them under normal feeding conditions. Since growth factors such as EGF and FGF were reported to be involved in angiogenesis, which is considered to play an important role in ulcer healing $(34,35)$, the effect of aging on angiogenesis should be considered as well.

Recently, we reported that unilateral vagotomy (36) and liquid diet ingestion (12) shrink ulcer size, suggesting the involvement of the inhibition of gastric distension. Since Konturek et al. (37) indicated that ulcer healing rate is dependent on its initial size, it is possible that shrinkage of ulcer size causes ulcer healing. In the present study, we found that the length of the ruptured muscularis mucosa in aged animals was significantly less than that in young animals, indicating that aging promotes tissue contraction. Indeed, the daily food consumption was similar in young and aged animals, while the stomachs of aged animals were bigger than those of young animals. Furthermore, the contraction of the gastric wall induced by electric vagal stimulation was almost the same in both groups, while the relaxation under the condition of pretreatment with atropine or phentolamine was sig- 
nificantly inhibited in aged animals. Considering these findings, the daily stomach distension in aged animals is considered to be inhibited. Therefore, as to the gastric distension, aging seemed to accelerate the healing of gastric ulcers.

Thus, aging decreases gastric acid secretion and stomach relaxation, probably resulting in the promotion of ulcer healing, while aging decreases gastric mucosal blood flow at the ulcer margin and mucosal cell proliferation, probably resulting in retardation of ulcer healing. Therefore, the lack of an influence of aging on the healing rate of gastric ulcers can be explained by the counterbalance of positive and negative components for ulcer healing. The process of healing of gastric ulcers is generally believed to be similar to that of wound healing (38). Considering that several investigators reported that wound repair in aged subjects was delayed as compared to that in young subjects in man (39) and experimental animals (40), the healing of gastric ulcers should be delayed in aged animals. However, the present study showed that the healing rate of gastric ulcers in aged animals was almost the same as that in young animals. It is considered that the discrepancy between the healing of wounds and gastric ulcers can be explained by the existence of gastric acid and the movement of the stomach. Acid secretion and gastric distension, which are negative components for ulcer healing, were decreased in aged animals. Since it is possible that the quality of ulcer healing in aged animals is different from that in young animals, the response of gastric ulcers in aged animals to various antiulcer drugs may be different from that in young animals.

We concluded that aging had little or no effect on the development and healing rate of kissing gastric ulcers induced in rats, but the quality of ulcer healing was quite different between young and aged animals, probably resulting from various types of gastric dysfunction, including positive and negative components for ulcer healing caused by aging.

\section{Acknowledgments}

We wish to thank N.J. Halewood for critical reading of the manuscript and J. Udagawa, J. Kosaka, T. Tsukahara, S. Okano and $\mathrm{Y}$. Matsubara for their technical assistance.

\section{REFERENCES}

1 Khalil T, Singh P, Fujimura M, Townsend CM Jr, Greeley GH and Thompson JC: Effect of aging on gastric acid secretion, serum gastrin, and antral gastrin content in rats. Dig Dis Sci 33, $1544-1548$ (1988)

2 Majumdar APN, Maitra R and Edgerton EA: Gastric secretion during aging in rats and effect of pentagastrin (PG). Gastroenterology 94, A-278 (1988)

3 Archimandritis A, Alegakis G, Theodoropoulos G, Kalos A,
Drivas G and Melissinos K: Serum gastrin concentrations in healthy males and females of various ages. Acta Hepato-Gastroenterol 26, 58-63 (1979)

4 Majumdar APN, Edgerton EA, Dayal Y and Murthy SNS: Gastrin levels and trophic action during advancing age. Am J Physiol 254, G538-G542 (1988)

5 Holt PR and Yeh K: Aging and gastrin production: Changes in serum and antral gastrin concentrations in the rats. J Gerontol 44, M62-M65 (1989)

6 Kogir M, Ishizuka J, Parekh D, Greeley GH and Thompson JC: Effects of aging on gastrin and somatostatin secretion from isolated perfused rat stomach. Dig Dis Sci 38, 303-308 (1993)

7 Masuda $\mathrm{Y}$, Ohno $\mathrm{T}$, Uramoto $\mathrm{H}$ and Ishihara $\mathrm{T}$ : Effects of aging on gastric secretion and blood flow in rats. In Mechanisms of Injury, Protection and Repair of the Upper Gastrointestinal Tract, Edited by Garner A and O'Brien PE, pp 309-317, John Wiley \& Sons, Chichester (1991)

8 Kim SW, Parekh D, Townsend CM and Thompson JC: Effects of aging on duodenal bicarbonate secretion. Ann Surg 212, $332-338(1990)$

9 O'Brien PE, Penney A, Lyons K, Comper W and Andrews F: Local influences on experimental ulcer healing. Digestion $\mathbf{5 5}$, Supp 2, 31 (1994)

10 Boyd EJS and Wormsley KG: Etiology and pathogenesis of peptic ulcer. In Gastroenterology, Vol 2, Edited by Haubrich WS, Kalser MH, Roth JLA and Schaffner F, pp 1013-1059, Saunders, Philadelphia (1985)

11 Ogihara Y and Okabe S: Mechanism by which indomethacin delays gastric ulcer healing in the rat: Inhibited contraction of the ulcer base. Jpn J Pharmacol 61, 123-131 (1993)

12 Tsukimi Y and Okabe S: Acceleration of healing of gastric ulcers induced in rats by a liquid diet. Importance of tissue contraction. Jpn J Pharmacol 66, 405-412 (1994)

13 Tsukimi $Y$ and Okabe S: Validity of kissing gastric ulcers induced in rats for screening of antiulcer drugs. J Gastroenterol Hepatol 9, S60-S65 (1994)

14 Anson ML: The estimation of pepsin, trypsin, papain and cathepsin with hemoglobin. J Gen Physiol 22, 79-89 (1938)

15 Johnson LR and Guthrie PD: Mucosal DNA synthesis: a shortterm index of the trophic action of gastrin. Gastroenterology 67, 453-459 (1974)

16 Burton K: A study of the conditions and mechanism of the diphenylamine reaction for the colorimetric estimation of deoxyribonucleic acid. Biochemistry 62, 315-323 (1956)

17 Giles KW and Mayers A: An improved diphenylamine method for the estimation of deoxyribonucleic acid. Nature 206, 93 (1965)

18 Takeuchi $\mathrm{K}$, Ueki S and Okabe S: Importance of gastric motility in the pathogenesis of indomethacin-induced gastric lesions in the rat. Dig Dis Sci 31, 1114-1121 (1986)

19 Takeuchi K, Ohuchi T and Okabe S: Endogenous nitric oxide in gastric alkaline response in the rat stomach after damage. Gastroenterology 106, 367-374 (1994)

20 Ohno T, Uramoto H, Ishihara T and Okabe S: Effects of 16,16dimethyl prostaglandin $E_{2}$ on surface epithelial cell damage in the rat stomach induced by vagal nerve stimulation. Jpn J Pharmacol 43, 429-439 (1987)

21 Hiramatsu $Y$ and Okabe S: Effect of combined administration of indomethacin and histamine on healing of acetic acid ulcers in rats. Digestion 49, Supp 1, 37 (1991) 
22 Yamamoto O, Okada Y and Okabe S: Effects of a proton pump inhibitor, omeprazole, on gastric secretion and gastric and duodenal ulcers or erosions in rats. Dig Dis Sci 29, 394-401 (1984)

23 Inauen W, Wyss PA, Kayser S, Baumgartner A, Scheurer-Maly CC, Koelz HR and Halter F: Influence of prostaglandins, omeprazole, and indomethacin on healing of experimental gastric ulcers in the rat. Gastroenterology 95, 636-641 (1988)

24 Johnson LR and Tumpson DB: Effect of secretin on histaminestimulated secretion in the gastric fistula rat. Proc Soc Exp Biol Med 133, 125- 127 (1970)

25 Ikezaki $M$ and Johnson LR: Development and sensitivity to different secretagogues in the rat stomach. Am J Physiol 244, G165-G170 (1983)

26 Hirose $\mathrm{H}$, Takeuchi $\mathrm{K}$ and Okabe S: Effect of indomethacin on gastric mucosal blood flow around acetic acid-induced gastric ulcers in rats. Gastroenterology 100, 1259-1265 (1991)

27 Brzozowski T, Konturek SJ, Majka J, Drozdowicz D, Stachura $\mathrm{J}$ and Nauert $\mathrm{C}$ : Involvement of nitric oxide in gastric ulcer healing with antacid. Eur J Gastroenterol Hepatol 5, Supp 3, S117-S123 (1993)

28 Cryer B, Redfern S, Goldschmiedt M, Lee E and Feldman M: Effect of aging on gastric and duodenal mucosal prostaglandin concentrations in humans. Gastroenterology 102, 1118-1123 (1992)

29 Goto $H$, Sugiyama $S$, Ohara A, Hoshino $H$, Hamajima E, Kanamori S, Tsukamoto $\mathrm{Y}$ and Ozawa $\mathrm{T}$ : Age-associated decreases in prostaglandin contents in human gastric mucosa. Biochem Biophys Res Commun 105, 954-964 (1982)

30 Smits GJM and Lefebvre RA: Influence of age on responsiveness of rat gastric fundus to agonists and to stimulation of intrinsic nerves. Eur J Pharmacol 223, 97-102 (1992)

31 Becker HD, Reeder DD and Thompson JC: The effect of changes in antral $\mathrm{pH}$ on the basal release of gastrin. Proc Soc
Exp Biol Med 143, $238-240$ (1973)

32 Takeuchi $\mathrm{K}$ and Johnson LR: Effects of cell proliferation on healing of gastric and duodenal ulcers in rats. Digestion 22. $92-100(1986)$

33 Konturek SJ, Brzozowski T, Dembinski A, Warzecha Z, Konturek PK and Yanaihara N: Interaction of growth hormone-releasing factor and somatostatin on ulcer healing and mucosal growth in rats; role of gastrin and epidermal growth factor. Digestion 41, 121-128 (1988)

34 Konturek SJ, Dembinski A, Warzecha Z, Brzozowski T and Gregory H: Role of epidermal growth factor in healing of chronic gastroduodenal ulcers in rats. Gastroenterology 94, 1300- 1307 (1988)

35 Folkman J, Szabo S, Stovroff M, McNeil P, Li W and Shing Y: Duodenal ulcer; discovery of new mechanism and development of angiogenic therapy that accelerates healing. Ann Surg 214, 414-427 (1991)

36 Tsukimi $Y$ and Okabe S: Effect of anterior unilateral vagotomy on healing of kissing gastric ulcers induced in rats. Jpn $\mathbf{J}$ Pharmacol 66, 105-114 (1994)

37 Konturek SJ, Stachura J, Radecki T, Drozdowicz D and Brzozowski $\mathrm{T}$ : Cytoprotective and ulcer healing properties of prostaglandin $E_{2}$, colloidal bismuth and sucralfate in rats. Digestion 38, $103-113$ (1987)

38 Boyd IS and Wormsley KG: Etiology and pathogenesis of peptic ulcer. In Gastroenterology, Vol 2, Edited by Berk J, Haubrich WS, Kalser MH, Roth JLA and Schaffner F, pp 1013-1059, Saunders, Philadelphia (1991)

39 Grove GL: Age-related differences in healing of superficial skin wounds in humans. Arch Dermatol Res 272, 381-385 (1982)

40 Bednar B and Mann M: The course of cutaneous wounds in young and old rats. Cesk Patol 12, 123-131 (1976) 